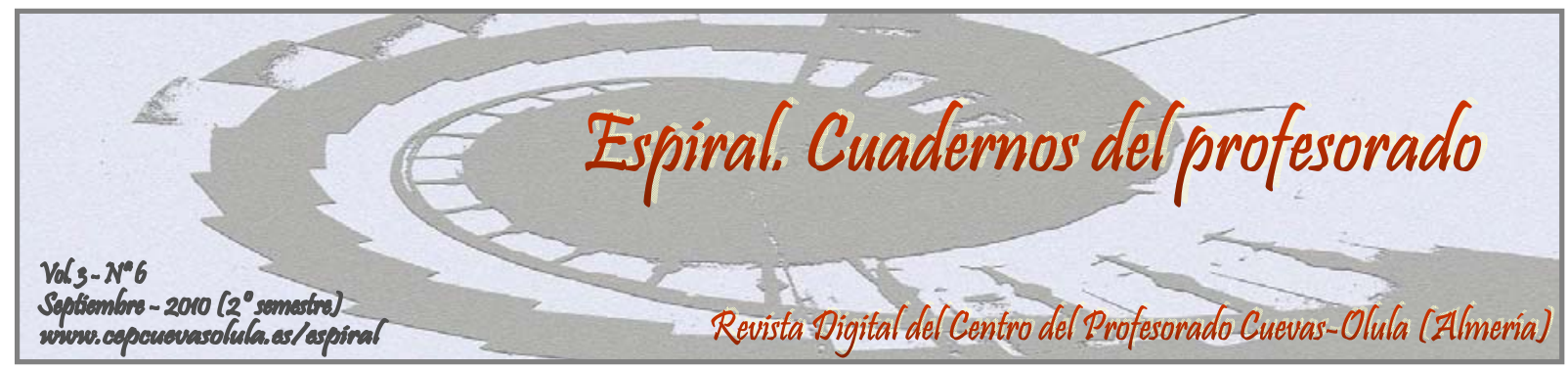

\title{
LA COMPETENCIA EN COMUNICACIÓN LINGÜÍSTICA A PARTIR DE LA CORRECCIÓN DE TEXTOS PERIODÍSTICOS: UNA EXPERIENCIA DOCENTE
}

\section{COMPETENCE IN LINGUISTIC COMMUNICATION FROM JOURNALISTIC STYLE AND COPYEDITING: A TEACHING EXPERIENCE}

\author{
Francisco José Rodríguez Muñoz
}

\author{
Departamento de Filología, Área de Lengua Española, Universidad de Almería, España
}

\begin{abstract}
RESUMEN: La competencia lingüístico-comunicativa es una noción amplia que incluye diferentes aproximaciones (por ejemplo, componentes de tipo gramatical, sociolingüístico, discursivo o textual, estratégico, socio-cultural y pragmático). Resulta complicado combinar todas estas perspectivas en un diseño educativo único y coherente. En este artículo, proponemos una unidad didáctica adaptada al 3er curso de ESO (Educación Secundaria Obligatoria) en la que hemos tratado de integrar los principales niveles para la enseñanza de la Lengua Española, intentando mejorar su uso normativo. Para lograr este objetivo, desarrollaremos una actividad individual en nuestra unidad didáctica (de acuerdo con los objetivos de enseñanza/aprendizaje, contenidos, recursos y criterios de evaluación para un programa de cien minutos). Posteriormente, concluiremos con las implicaciones pedagógicas que se derivaron a partir de nuestra práctica en el aula. La evaluación de los dos grupos (B y C) reveló resultados de aprendizaje desiguales; sin embargo, los estudiantes aumentaron su participación en clase, así como sus intereses en el conocimiento del estilo periodístico y en las tareas de edición y corrección textual. Finalmente, recomendamos a los profesores aplicar esta propuesta pedagógica en niveles superiores de la asignatura Lengua Española.
\end{abstract}

Palabras clave: Lengua Española, unidad didáctica, competencia en comunicación lingüística, estilo periodístico, corrección textual.

ABSTRACT: Linguistic-communicative competence is a wide notion that includes different approaches (for example, grammatical, sociolinguistic, discursive or textual, strategic, socio-cultural and pragmatic components). It is difficult to combine all these perspectives in a single and coherent educational design. In this paper, we propose a didactic unit adapted to the 3rd form of ESO (Compulsory Secondary Education) in which we have tried to integrate the main levels for teaching Spanish Language and for improving its normative use. To achieve this purpose, we will develop an individual activity in our didactic unit (according to the teaching/learning objectives, contents, resources and evaluation criteria for a hundred minutes program). Then we will conclude with the pedagogical implications of our classroom practice. The evaluation of two groups (B and C) showed unequal learning results, but students increased their participation in class and their interests in journalistic style knowledge and copyediting tasks. Finally, we recommend that teachers apply this pedagogic proposal in higher levels of Spanish Language subject.

Key words: Spanish Language, didactic unit, competence in linguistic communication, journalistic style, copyediting. 
Rodríguez Muñoz, F.J. (2010). La competencia en comunicación lingüística a partir de la corrección de textos periodísticos: una experiencia docente. Espiral. Cuadernos del Profesorado [en línea], 3(6), 53-64. Disponible en: http://www.cepcuevasolula.es/espiral.

Fecha de recepción: 17/03/2010

Fecha de aceptación: 27/07/2010
Enviar correspondencia a: frodriguez@ual.es

\section{1.- INTRODUCCIÓN.}

Como primera aproximación al análisis y el uso de la lengua española en los medios de comunicación escritos en Educación Secundaria Obligatoria (ESO), puede resultar muy operativa una propuesta didáctica fuera de lo común en los currículos escolares de esta etapa, como es la corrección de estilo periodístico.

Esta labor filológica, no demasiado conocida, lo es aún menos en la actualidad, debido al gran desarrollo de los modernos procesadores de texto que integran, en su funcionamiento ordinario, correctores automáticos de errores ortográficos y gramaticales. Sin embargo, su puesta en práctica como material de enseñanza puede ser atractiva y motivadora para el discente, toda vez que en ella se sintetizan los distintos planos de la lengua, lo que supone una actualización de los conocimientos que el hablante posee de la lengua, así como un desarrollo competencial significativo de la capacidad de emitir juicios críticos a partir de argumentos propiamente lingüísticos.

No obstante, es la competencia comunicativa (RD 1631/2006, de 29 de diciembre, por el que se establecen las enseñanzas mínimas de Educación Secundaria) la que adquiere un mayor protagonismo en nuestra propuesta.

Además de presentar la unidad didáctica, adaptada a un nivel de tercer curso de ESO, daremos cuenta de la explicación conceptual de cada uno de los apartados que la forman. En segundo lugar, comentaremos las implicaciones y los resultados que tuvo la aplicación de esta unidad didáctica en un Centro de educación catalán durante el curso 2007/2008.

Por tanto, nuestro objetivo tiene carácter expositivo y, a la vez, es crítico y descriptivo. Nos interesa, en primer lugar, poner de relieve la necesidad de desarrollar una competencia curricular transversal como es la lingüísticocomunicativa, referida a la comprensión y expresión eficaz en la propia lengua, en nuestro caso la española. En la tarea docente, resulta a veces complicado ofrecer fundamentos para el análisis y el uso del propio idioma que se vean integrados en planteamientos didácticos coherentes con los contenidos y con la metodología que presentan y que, al mismo tiempo, sean propuestas atractivas y motivadoras para el estudiante de Secundaria.

Asimismo, nos parece conveniente relatar la experiencia docente, de acuerdo con nuestros planteamientos, que resultó de la aplicación de esta unidad en la clase de Lengua Española. Con ello, pretendemos resaltar la viabilidad de esta propuesta didáctica para futuras aplicaciones similares o que pudieran derivarse de la misma. Por otro lado, destacamos las posibles repercusiones que la aplicación de esta competencia puede tener para la totalidad del currículum en general.

\section{1.- Acerca de la competencia lingüístico- comunicativa.}

En el marco de las propuestas realizadas por la Unión Europea, la competencia en comunicación lingüística queda identificada como una de las ocho competencias básicas, junto con la matemática, la de conocimiento e interacción con el mundo físico, tratamiento de la información y competencia digital, la competencia social y ciudadana, la cultural y artística, la competencia para aprender a aprender y la de autonomía e iniciativa personal (Ley Orgánica de Educación 2/2006, de 3 de mayo).

En el modelo de Canale (1983), la competencia comunicativa estaría sustentada por otras cuatro que se implican entre sí: las competencias lingüística, sociolingüística, discursiva y estratégica. A las que Van Ek (1986) añade las competencias de tipo social y cultural.

Desde una perspectiva funcional, Hymes (1971) relaciona esta macro-competencia de carácter transversal con saber «cuándo hablar», "cuándo no hablar», "de qué hablar», «con quién», «cuándo», «dónde» y «en qué forma». Enfoque que, por otra parte, entronca con las 
cuatro máximas de cooperación que postula Grice (1975): cantidad, calidad, manera y pertinencia.

El marco que proporciona actualmente la metapragmática (Caffi, 1998; Reyes, 2002; Verschueren, 2002), entendida como el estudio del uso reflexivo del lenguaje que hacen los hablantes, constituye un paso más en las definiciones conceptuales del conjunto de destrezas diversas que recoge la capacidad lingüístico-comunicativa.

En otras palabras, la competencia metapragmática se refiere al conocimiento que tiene el propio hablante de las relaciones existentes dentro del sistema y entre el sistema lingüístico y el contexto comunicativo en que se produce. Por tanto, esta competencia es la que permite al usuario distinguir el mensaje lingüístico del contexto extralingüístico y establecer conexiones entre ambos (Gombert, 1999; Pratt y Nesdale, 1984).

Para Portolés (2004), la conciencia metapragmática se relaciona con la capacidad que tienen los hablantes al optar por enunciados que lleven al interlocutor a un estado mental congruente con la intención que se pretende comunicar.

Los conocimientos pragmáticos de los que más o menos son conscientes los usuarios permiten escoger formulaciones lingüísticas adecuadas a cada contexto comunicativo. La conciencia metapragmática se concretaría, por tanto, en la capacidad de selección de una formulación apropiada para cada momento de comunicación.

En resumen, la diversidad y la transversalidad que subyacen en las concepciones teóricas de esta competencia deben reflejarse también en las propuestas prácticas y metodológicas que puedan derivarse de ella. Esto es, pensamos que nuestro esfuerzo como docentes debe ir encaminado al enfoque holístico de cada una de las competencias, en particular, la competencia comunicativa permite «una configuración psicológica que comprende las capacidades cognitivas y metacognitivas para comprender y producir significados, los conocimientos acerca de las estructuras lingüísticas y discursivas y las habilidades $\mathrm{y}$ capacidades para interactuar en diversos contextos socioculturales, con diferentes fines y propósitos» (Romeo et al., 2007).

\section{2.- DESARROLLO CONCEPTUAL DE LA UNIDAD DIDÁCTICA: LA CORRECCIÓN DE ESTILO PERIODÍSTICO.}

\section{1.- La profesión de corrector de estilo perio- dístico.}

La corrección de estilo periodístico es una de las posibles salidas profesionales que tienen los filólogos y los lingüistas. Concretamente, aquellos que se han especializado en el correcto uso de una lengua particular, como es el caso del español (Filología y Lingüística Hispánicas).

Se trata de un trabajo normalmente no muy bien remunerado, pero la figura del corrector de estilo es indispensable en la redacción de cualquier medio periodístico. En las redacciones, los redactores y colaboradores -que no siempre son periodistas ni tampoco todos han tenido que pasar por facultades de ciencias de la información- son los encargados de elaborar los textos en cualquiera de sus subgéneros posibles (noticias, artículos de opinión, columnas, reportajes, editoriales, etc.). A pesar de ser usuarios de la lengua, generalmente no son especialistas. Por ello, es habitual que cometan errores inconscientes, a veces motivados por la prisa (las noticias caducan en el momento en que son noticia) y, otras, por el desconocimiento de ciertos usos lingüísticos. Es ahí donde encuentra justificación el trabajo como corrector.

Los correctores pueden realizar sus funciones en soportes electrónicos o, como tradicionalmente se ha venido haciendo, corrigiendo directamente sobre el papel. Esta última opción exige que se apliquen símbolos fácilmente comprensibles por el redactor que, más tarde, tendrá que introducir los cambios sugeridos por el corrector en el programa informático que se utilice en la redacción (o bien el conocimiento de un código común de símbolos por parte de correctores y redactores, hecho poco habitual en las redacciones pequeñas o de carácter local).

Por último, el papel de corrector periodístico tiene un valor social relativo, ya que quien supervisa su trabajo suele ser algún subdirector del periódico y, en redacciones más pequeñas, puede encargarse directamente el director. Esto significa que son personas no especialistas que, con frecuencia, no tienen demasiado que apuntar o sugerir en el proceso de corrección textual. Por tanto, el poder del corrector de estilo reside en 
que sus manos son prácticamente las últimas por las que pasa la información y los datos que al día siguiente llegaran a las del lector.

\section{2.- El libro de estilo periodístico.}

La principal herramienta de un corrector de estilo son, sin lugar a dudas, los diccionarios (generales de la lengua, de sinónimos y antónimos, de dudas y dificultades). Sin embargo, existen ciertas convenciones establecidas por los medios informativos, esto es, códigos internos que tratan de unificar sistemas y formas expresivas, con el fin de dar personalidad al propio medio y facilitar la tarea del lector. Estas normas impuestas por cada medio se recogen en los libros de estilo (también denominados hojas de estilo o libros de hojas de estilo) y junto con los diccionarios y, en menor medida, las gramáticas son los argumentos de autoridad a los que recurre el corrector de estilo cuando realiza su labor.

\section{Estructura.}

Por lo general, en los libros de estilo de medios informativos de alcance nacional (como El Mundo o El País), la (macro)estructura viene dada por un prólogo o introducción donde suelen exponerse los objetivos de la obra que, en caso de que cuente con varias ediciones, pueden presentar algunas variaciones.

En segundo término, el cuerpo del libro de estilo suele contener principios teóricos sobre el tratamiento de la información en los distintos géneros periodísticos, aspectos relacionados con la titulación, la tipografía (tipos de letra: uso de cursiva, mayúscula, negrita), los signos ortográficos (uso de comillas -“...”, «...»-, paréntesis, corchetes), pies de fotos y gráficos, tratamiento y protocolo, nombres propios de persona y lugar (antropónimos, topónimos y gentilicios), números, pesos y medidas, errores frecuentes, entre otros.

Ahora bien, la sección principal en el cuerpo del libro de estilo es el diccionario. Aquí es donde cada medio puede discrepar en mayor o menor medida con los postulados académicos (Diccionario de la Real Academia, 2001; Diccionario Panhispánico de Dudas, 2005) y donde se incluyen unidades léxicas con significado ambiguo o dudoso, así como sugerencias de adaptación de extranjerismos y grafías de siglas. En consecuencia, no se trata de un diccionario general de la lengua, sino de una selección de los vocablos que los editores consideran más problemáticos. Es preciso advertir que no siempre el libro de estilo es el vademécum del redactor periodístico, ya que la lengua es cambiante y cada día aparecen palabras nuevas cuyo uso no viene siempre especificado en los libros de estilo (mileurista, crack, alunizar). Lo mismo podemos apuntar en relación con la grafía de algunas siglas (existen vacilaciones de escritura como ocurre con $D J$, $d j$, deejay, disc jockey, disyóquey).

Por último, en algunos libros de estilo pueden aparecer anexos o apéndices de contenido variable (p. ej.: estatutos del periódico, signos de corrección, etc.).

\section{Ejemplos.}

Conviene que nuestros alumnos tengan un referente físico de lo que es un libro de estilo periodístico, de cara al desarrollo de esta unidad. En nuestra experiencia didáctica, se mostró un ejemplo en papel de un libro de estilo. Concretamente, elegimos el de El País (decimoquinta edición, 1999), por encontrarse disponible en el seminario de Lengua y Literatura Españolas del Centro en el que trabajamos.

\section{3.- Criterios de corrección periodística.}

El criterio que emplea el corrector de estilo periodístico es eminentemente normativo $o$ prescriptito, ya que se atiene a las normas y reglas de la lengua empleada en la redacción del texto. No obstante, ocasionalmente puede aplicarse un criterio descriptivo cuando no existen normas en relación con algún aspecto lingüístico o cuando la normativa es confusa o contradictoria (p. ej.: en las cuestiones de género, el DRAE 22 ${ }^{\mathrm{a}}$ ed. [2001] admite el género femenino en sustantivos como concejal, $-a$; sin embargo, el DPD [2005] considera que este nombre es ambiguo en cuanto al género el/la concejal, mostrándose más conservador al respecto: aprendiz, $-a$, comediante, $-a$ ). Asimismo, a veces, tampoco se aclaran dudas que atañen a ciertos gentilicios, como puede ser el caso de Sidney donde la Academia concluye: «No existe gentilicio español para este topónimo» (DPD, 2005) cuando una propuesta clara podría ser sidneyano. En estos ejemplos, el corrector de estilo debe aplicar un criterio puramente descriptivo y deductivo, propiciado por el uso más generalizado y común en la lengua («la lengua la hace el uso y el vulgo»).

En suma, las tareas del corrector de estilo se concretan en tres niveles lingüísticos fundamentalmente: el ortográfico, el 
morfosintáctico (o gramatical) y el léxico. Además, también debe estar alerta de las cuestiones tipográficas, de maquetación $\mathrm{y}$, en ciertas ocasiones, de titulación (titulares, subtítulos y sumarios adecuados al contenido).

Por consiguiente, las correcciones no solo conciernen al plano formal, sino que a menudo tocan el plano de los contenidos y el significado.

\section{Ortografía.}

Hay que ser conscientes de la importancia que tiene la norma para la correcta estructuración de una lengua, para su establecimiento y conservación, así como para la difusión eficaz de la información y, en definitiva, para hacer posible la comunicación escrita.

La correcta grafía de las palabras es un factor principal en la revisión de los textos periodísticos. A pesar de que existen modernos procesadores de texto que incluyen un corrector ortográfico automático (Microsoft Word), no siempre las soluciones que nos ofrecen y las modificaciones que ejecutan son fiables $u$ oportunas (p. ej.: el corrector que integra Microsoft Word XP no reconoce y resalta palabras existentes como «maquetación» y modifica automáticamente nombres propios como «Nebrija» por «Lebrija»), errores que, con la diligencia que exige la redacción periodística y el descuido, pueden resultar fatales para el lector.

Por último, a veces se producen errores ortográficos que encuentran su razón de ser en los medios informáticos y mecanográficos. Por ejemplo, la causa de que aparezcan en portadas de tirada nacional errores de confusión entre la $b$ y la $v$ en palabras de uso común como bola o veloz podría deberse a que ambas teclas aparecen juntas en los teclados con alfabeto latino.

\section{Sintaxis.}

La construcción de oraciones en el texto periodístico debe caracterizarse básicamente por la aplicación de las clásicas propiedades en la disposición textual escrita de corrección, claridad, cohesión y concisión.

Por tanto, en la sintaxis periodística deben colocarse adecuadamente los constituyentes de la frase (sujeto + verbos + complementos), intentando no alterar el orden gramatical y lógico de los enunciados. Deben ser oraciones gramaticalmente correctas. Hay que recordar que el hipérbaton es la figura retórica que consiste en la alteración del orden de los componentes oracionales y el texto periodístico debe buscar la claridad y la monosemia, debe huir pues de todo recurso retórico y estilístico que genere ambigüedad y polisemia significativa. No obstante, en ciertos reportajes y, especialmente, en los artículos de opinión, definidos estos últimos por la subjetividad, circunstancialmente puede hacerse uso de estos recursos expresivos.

Asimismo, conscientes de estas pocas excepciones, los textos periodísticos (sobre todo la noticia, «el texto periodístico por antonomasia») prefieren las oraciones simples, separadas por punto y seguido, bien articuladas entre sí y cohesionadas adecuadamente con el resto de enunciados.

Algunos errores habituales que afectan a la sintaxis son: confusión de estilo directo e indirecto, uso inapropiado de los impersonales, desorden en la información (frases que ocupan un párrafo), comas que separan el sujeto de su verbo, etc.

\section{Léxico.}

Es este el aspecto más cambiante de la lengua y el que suele plantear más problemas en la corrección periodística. De ahí que el diccionario se convierta en la herramienta clave del corrector de estilo.

El léxico periodístico debe contemplar la correcta adaptación y el uso de ciertos neologismos. Hay que tener en cuenta las sugerencias del libro de estilo (si existieran) y de la Academia (que diariamente enmienda sus artículos lexicográficos) en las adaptaciones de extranjerismos (anglicismos como bullying, mobbing), aunque no se sigan a rajatabla (p. ej.: es evidente que la grafía más extendida de whisky es la correspondiente a la voz inglesa y no su adaptación al español, güisqui -otros ejemplos polémicos son, por ejemplo, cáterin, parquin, campin, ranquin, delicatesen-). Sobre todo, es conveniente evitar barbarismos que tengan un equivalente en nuestra lengua o que atenten contra las normas ortográficas (p. ej.: pack, set, kit por juego, conjunto; recordando que, en español, las sílabas nunca acaban en oclusiva).

Por otra parte, el léxico periodístico también debe procurar la claridad. Por ello, conviene evitar los extremos y minimizar el uso de cultismos (p. ej.: latinismos poco extendidos como id est, hic et nunc, magnis itineribus; aunque puedan emplearse otros más usuales y fácilmente reconocibles como in situ, a priori, a posteriori). Del mismo modo, es preciso desterrar 
por completo el uso de vulgarismos (p. ej.: redonda por rotonda) y palabras dialectales o dialectalismos que puedan dificultar la comprensión interlingüística (p. ej.; yampo, présul o chícharo, en el léxico andaluz), arcaísmos (azafate, léxico andaluz), palabras de jerga (tecnicismos médicos como pirosis en vez de acidez de estómago), argot y acortamientos léxicos (legía por legionario).

Otro aspecto que hay que corregir es el que afecta a los archisílabos o polisílabos (moda sesquipedálica), el gusto por alargar incoherentemente las palabras: influenciar por influir, posicionar por poner (a menos que posicionar se use en el sentido de adoptar una posición o actitud con respecto a un tema), concretizar por concretar, temática por tema, culpabilizar por culpar, contabilizar por contar.

Es frecuente también que, por descuido del redactor, se reproduzca una misma palabra varias veces en el texto. Conviene, pues, buscar sinónimos (u otros mecanismos correferenciales) cuando un vocablo se repite excesivamente o cuando se encuentra en enunciados próximos entre sí.

\section{Cuestiones tipográficas, maquetación y titulación.}

Desde el punto de vista tipográfico, cada periódico debe establecer sus propias convenciones. Generalmente, los títulos (titulares), los subtítulos y la entradilla aparecen en negrita y el tamaño de la letra es mayor en ellos. El cuerpo de los textos (noticias, reportajes, entrevistas, etc.) se dispone en redonda, excepto los extranjerismos, los títulos de libros y películas y ciertas palabras que pueden resultar ambiguas debido a su polisemia (p. ej.: populares cuando se refiere a los miembros del Partido Popular) que se suelen escribir en cursiva (en ocasiones, las palabras de uso coloquial aparecen en cursiva o entrecomilladas en la entrada y los títulos). En los titulares, los subtítulos y la entradilla, las palabras que deberían aparecer en cursiva lo suelen hacer con comillas simples ('...'), ya que estas partes van en negrita. La presencia de las mayúsculas es prácticamente nula.

En cuanto a la maquetación, el corrector debe estar pendiente de que márgenes, sangrías, espacios e interlineado hayan sido procesados debidamente por el redactor en la aplicación informática donde ha introducido su texto. Con respecto a la sangría, en las ediciones impresas el primer párrafo generalmente no se sangra, tampoco la entradilla, ya que se distingue visualmente dónde comienzan. El resto de párrafos deben disponerse convenientemente sangrados.

Finalmente y en relación con el contenido, el corrector ha de supervisar no solo que el titular sea gramatical, léxica y ortográficamente correcto, sino que también en el plano del contenido recoja y compendie en una frase todo aquello y solo aquello que es imprescindible para la comprensión del texto. Una norma que puede extenderse a la mayoría de publicaciones en prensa escrita es que no pueden aparecer las mismas palabras o datos en el titular y en el subtítulo.

Para concluir, los titulares han de centrar la atención del lector e imponerle su contenido. Por lo tanto, deben buscar la concreción y evitar en lo posible el sensacionalismo. La claridad es la principal característica que define a los titulares y nunca se ha de sacrificar esta a causa de la brevedad.

En relación con las cuestiones (macro) estructurales, conviene especificar a los alumnos la distribución jerárquica de la información en el género periodístico que trabajaremos: la noticia (figura 1).

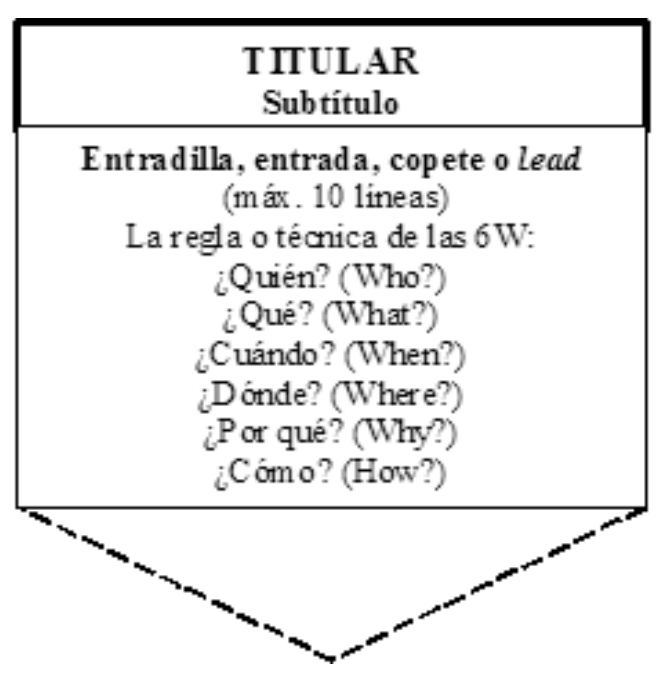

Figura 1.- Estructura jerárquica de la noticia.

\section{3.- EXPERIENCIA DOCENTE.}

En este apartado daremos cuenta de la aplicabilidad sobre la unidad didáctica de corrección periodística que llevamos a cabo, en el Departamento de Lengua y Literatura Españolas, durante las prácticas docentes desarrolladas para el curso 2007/2008 en el IES Fort Pius (Barcelona). 


\section{1.- Contextualización general del Centro.}

El IES Fort Pius es un centro público de Enseñanza Secundaria situado en la zona centro de Barcelona, en la parte derecha del distrito del Eixample (Ausiàs March 78, 08013). Recibe una tipología variada de alumnado procedente de diversos colegios de Educación Primaria y cuenta con una ratio elevada de alumnos extranjeros.

Durante el año académico 2007/2008 el Centro contó con tres líneas para los cursos de $1^{\circ}$, $3^{\circ}$ y $4^{\circ}$ de ESO (A, B y C), siendo dos las líneas de $2^{\circ}$ de ESO y Bachillerato (A y B).

Se trata de un Centro en el que no se aprecian grandes desigualdades sociales y donde el número de incidencias que se producen en el aula no va más allá de lo común.

\section{2.- Tarea, proceso y recursos.}

La tarea propuesta consistió en la corrección de un texto periodístico de información que fue proporcionado a cada alumno por el profesor. Seleccionamos dos noticias de actualidad (disponibles en versiones impresas de medios de prensa nacionales) que contenían errores de redacción. Además, decidimos incrementar el número de fallos ortográficos, léxicos, gramaticales y tipográficos, a fin de que el alumno pudiera captar un mínimo de seis o siete faltas en cada uno de los textos. Teniendo en cuenta el número de alumnos, propusimos dos modelos de textos informativos objeto de corrección estilística. En ambos casos, fueron textos breves, de entre quince y veinte líneas, que por su contenido podían resultar simpáticos o entretenidos a los alumnos. Se planteó, en todo caso, como una tarea individual, no en grupo.

La tarea fue realizada en casa -con la posibilidad de comenzarla en clase- y constó de dos partes diferentes que quedaron expresadas en los enunciados de cada modelo:

1.- Pon un titular y escribe un subtítulo para esta noticia.

2.- Revisa el texto aplicando los criterios propios de un corrector de estilo periodístico. Debes prestar especial atención a la ortografía, a la sintaxis, al léxico y, en lo posible, a la tipografía.

Los recursos electrónicos que aconsejamos para su utilización durante la tarea, todos ellos disponibles en la Red, fueron:

$$
<\text { www.rae.es }>(D R A E, D P D)
$$

$<$ http://estudiantes.elpais.es/libroestilo/in dice_estilos.htm>

$<$ http://www.elmundo.es/diccionarios/>

Se recordó previamente a los alumnos en qué aspectos lingüísticos debían detenerse para la corrección del texto, a fin de guiar la actividad y aclarar las consignas:

1.- Faltas ortográficas, puntuación.

2.-Léxico inadecuado: extranjerismos, polisílabos, vulgarismos, proponer sinónimos, evitar repeticiones de palabras que se encuentran próximas en el texto.

3.- Sintaxis deficiente: estructuras gramaticales mal construidas, errores de concordancia, confusiones de estilo directo y diferido, comas entre sujeto y verbo, comas antepuestas a conjunciones copulativas.

4.- Tipografía: extranjerismos y latinismos en cursiva, citas textuales entrecomilladas.

\section{3.- Evaluación.}

La corrección y evaluación de las pruebas, así como la posterior revisión que se llevó a cabo en una segunda sesión presencial, fueron tareas realizadas por un único profesor, el mismo que se ocupó de la exposición de la unidad didáctica y de la explicación y entrega de la actividad a los alumnos.

La puntuación fue de carácter cualitativo y se realizó en función de los siguientes criterios:

1.- La corrección, claridad y calidad de los titulares y subtítulos propuestos en la primera parte de la tarea.

2.- Errores de redacción apuntados por el alumno y posibles sugerencias para su sustitución. Para superar la actividad era necesario localizar, al menos, seis o siete errores de redacción.

Finalmente, la retroalimentación por parte del profesor ofreció indicaciones al alumno sobre sus aciertos, descuidos o fallos a la hora de revisar un texto periodístico. El grado de satisfacción con el trabajo realizado se especificó por medio de criterios convencionales de valoración cualitativa con los que está familiarizado el alumno: «excelente», «notable», «bien», «suficiente», «insuficiente».

\section{4.- Participantes.}

La unidad didáctica fue expuesta en dos grupos de tercer curso de Educación Secundaria, $3^{\circ}$ 


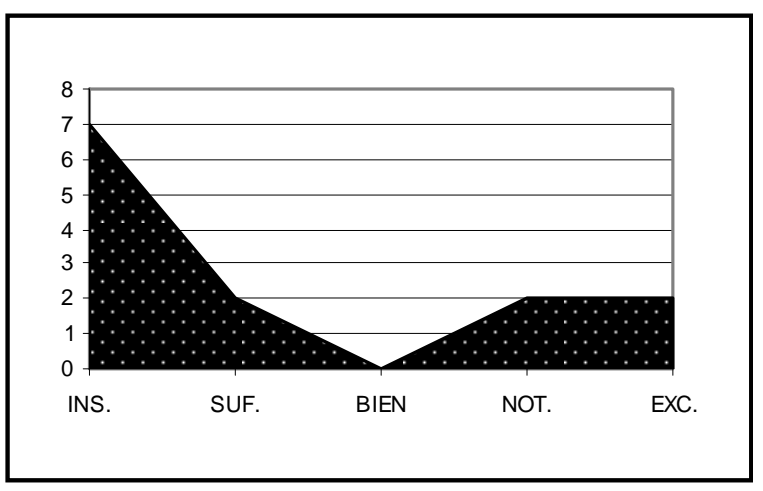

Figura 3.- Resultados $3^{\circ} \mathrm{ESO}$, grupo C.

ESO-B y $3^{\circ}$ ESO-C. Ambos grupos, formados por un total de veinticinco alumnos.

En $3^{\circ}$ ESO-B fueron completadas y devueltas diecinueve actividades de las veinticinco que se esperaban inicialmente. Por otra parte, en $3^{\circ}$ ESO-C se recogieron trece actividades.

\section{5.- Resultados de la actividad.}

En general, la calificación de las actividades fue una tarea complicada. Bien es verdad que, en muchos casos, estuvo bastante clara, pero no siempre ocurrió así. Hay que tener en cuenta, además, que no todos los alumnos realizaron el mismo esfuerzo al completar la actividad (por

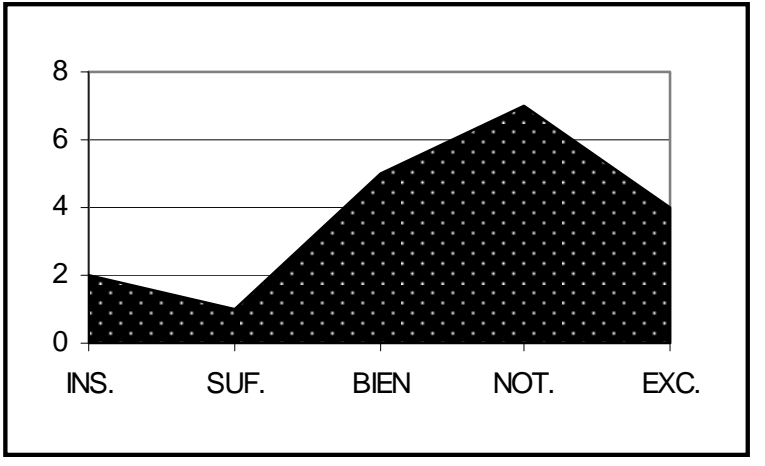

Figura 2.- Resultados $3^{\circ}$ ESO, grupo B.

ejemplo, si nos detenemos en el factor referido a la lengua materna, los estudiantes no nativos presentan más errores que los nativos por cuestiones de puro sentido común).

Asimismo, los resultados obtenidos por el grupo de $3^{\circ}$ ESO-B fueron significativamente mejores que los alcanzados por el grupo C. En concreto, cuatro actividades fueron calificadas con excelente, siete con notable, cinco con bien, una con suficiente $y$, finalmente, solo dos alumnos no consiguieron superar los objetivos de la actividad.

En segundo lugar, las calificaciones obtenidas por el grupo de $3^{\circ}$ ESO-C fueron: dos excelentes, dos notables, dos suficientes y siete insuficientes (entre los cuales se cuentan dos suficientes convertidos en insuficientes por copiar íntegramente la actividad).

De acuerdo con las puntuaciones de ambos grupos (ver fig. 2 y fig. 3), en $3^{\circ}$ ESO-B el rendimiento en este perfil sobre la competencia de comunicación lingüística fue mucho más elevado que en el grupo C. Una posible interpretación de este contraste en la evaluación de estos dos grupos de discentes responde a las variables que se refieren a los componentes de la actitud y a los preconceptos. Por una parte, en la experiencia de aula no percibimos un interés tan alto por la tarea de corrección periodística, sobre la que versó la unidad, como el que mostró el grupo B. Por ejemplo, este hecho se evidenció en el trabajo cooperativo que, durante el desarrollo de la unidad didáctica, fue mayor en este último grupo que en el grupo C. Por otra parte, los conocimientos previos sobre la estructura lingüística, entendida como sistema de sistemas potenciales, resultaron más completos en el grupo B (por ejemplo, en cuestiones relacionadas con la norma ortográfica, el léxico y la morfosintaxis). En todo caso, estas premisas se pusieron de manifiesto en la corrección de las pruebas y en la puntuación desigual de las actividades.

\section{6.- Conclusiones}

1. A partir de nuestra experiencia en el aula, comprobamos que la presentación de unidades didácticas fuera de los parámetros convencionales que imponen los libros de texto, en nuestro caso de la asignatura Lengua y Literatura (Área: Lengua Española), resulta cuando menos un factor atractivo y motivador para el alumnado.

2. Este marco general en el que inscribimos la competencia en comunicación lingüística permite, desde un punto de vista conceptual, ofrecer mecanismos de análisis y herramientas para la correcta expresión, en las modalidades oral y escrita, de la lengua española. Asimismo, despierta la conciencia del propio hablante, discente de lengua española, sobre los usos comunicativos del idioma (por ejemplo, al trabajar textos periodísticos de actualidad y en las secciones de información nacional).

3. La transversalidad, inherente a esta competencia, quedó confirmada en nuestra experiencia docente. Por ejemplo, al correlacionar con el pensamiento crítico y 
autocrítico a la hora de afrontar la lectura y el análisis de textos periodísticos contemporáneos al estudiante. No obstante, en nuestra experiencia didáctica, las competencias con las que más correlacionó la competencia lingüística fueron, en primer lugar, la social y ciudadana (comentarios referidos al futuro profesional, al desconocimiento de ciertas profesiones, al funcionamiento de los medios de masas y a la influencia social que ejercen estos) y, en segundo lugar, la competencia sobre tratamiento digital de la información resultó también de especial interés para nuestros alumnos de tercer curso de ESO (conocimientos sobre procesadores de texto, preguntas sobre programas informáticos utilizados en las redacciones periodísticas y cuestiones referidas a la edición).

4. Este principio de transversalidad que plantea nuestro planteamiento didáctico con respecto a otras competencias es mucho más amplio de lo que en principio pudiera parecer. Esto es, la lengua, como vehículo de comunicación, constituye el soporte básico del resto de materias que integran el currículum escolar y tiene implicaciones directas en el proceso de enseñanza/aprendizaje en cualquiera de los niveles académicos.

5. El planteamiento didáctico sobre corrección de textos periodísticos integra de manera sintética y coherente distintos planos y componentes lingüísticos que propician un eficaz desarrollo conceptual en clase y, por otra parte, todos estos elementos lingüísticos se aprovechan, se actualizan y se ponen en práctica durante el desarrollo de la actividad.

6. Debido a la aplicabilidad y operatividad de esta propuesta docente, el diseño de esta unidad puede resultar potencialmente aconsejable para el desarrollo de nuevas actividades formativas, tal vez más enfocadas a cada uno de los niveles de análisis y uso lingüísticos, en cursos de enseñanza posteriores.

\section{4.- APORTACIONES A LA COMUNIDAD EDUCATIVA.}

Las repercusiones derivadas de este planteamiento didáctico y de la subsiguiente experiencia docente que referimos en este trabajo pueden resultar especialmente relevantes para el docente de Lengua Española en cursos de Enseñanza Secundaria Obligatoria.

Frente a los enfoques tradiciones que presentan los currículos normalizados y que habitualmente vienen impuestos por los libros de texto, proponemos un modelo alternativo con el que trabajar una competencia transversal y necesaria para el estudiante en su vida cotidiana, como es la comunicación lingüística en la propia lengua.

Son generalizables las quejas y comentarios de los docentes de Lengua Española, en particular, así como de otras materias que integran el currículum escolar, sobre el mal uso de la lengua al redactar pruebas y actividades. Una forma de despertar conciencias y aprender a evitar estas incorrecciones puede verse respaldada por el diseño de planteamientos didácticos como el nuestro, que ayuden a la explicación y detección de irregularidades lingüísticas en textos escritos, como es el caso de los géneros periodísticos.

Estas pautas de actuación docente, según indica nuestra experiencia, resultan bastante acertadas para alumnos que se encuentran escolarizados en el segundo ciclo de Educación Secundaria. A pesar de que nuestra propuesta didáctica se presta especialmente al análisis microestructural de los elementos lingüísticos que infringen los criterios de corrección en distintos planos lingüísticos, el trabajo con textos periodísticos en la clase de Lengua Española podría resultar igualmente operativo en niveles más generales del ámbito comunicativo. Por ejemplo, en tareas de análisis y síntesis de la información, búsqueda de temas y argumentos, entre otras funciones comunicativas que se identifican más específicamente con los niveles superestructurales y macroestructurales de la lengua. Este tipo de actividades podría redundar, además, en la mejora de técnicas de estudio, ofreciendo bases instrumentales para su adquisición y desarrollo, y tareas relacionadas con otras materias curriculares, dada la transversalidad de nuestro planteamiento.

Debido a este carácter transdisciplinar, este ejemplo de actuación educativa permite, sin lugar a dudas, potenciar valores en distintas direcciones y fomentar el pensamiento crítico del estudiante que se enfrenta a un texto determinado.

Por tanto, debemos hacer hincapié en la necesidad de elaborar un currículum flexible y estratégico que sea enriquecido por las experiencias prácticas y que, en último término, se adapte a las demandas actuales de los discentes. Esta nueva concepción curricular solo 
es posible a partir de la exposición de los propios planteamientos y el análisis de nuestras experiencias docentes que, en un proceso de revisión en forma de espiral, permita rediseñar y establecer el conjunto de criterios didácticometodológicos que lo reciclen y recompongan.

\section{5.- REFERENCIAS BIBLIOGRÁFICAS.}

BOE (2006). Real Decreto 1631/2006, de 29 de diciembre, por el que se establecen las enseñanzas mínimas de Educación Secundaria. Madrid: Ministerio de Educación.

Caffi, C. (1998). Metapragmatics. En J. L. Mey (ed.), Concise Encyclopedia of Pragmatics (pp. 581586). Amsterdam: Elsevier.

Canale, M. (1983). De la competencia comunicativa a la pedagogía comunicativa del lenguaje. En Llobera et al. (1995). Competencia comunicativa. Documentos básicos en la enseñanza de lenguas extranjeras (pp. 63-83). Madrid: Edelsa.

El Mundo (2001). Diccionarios. Disponible en: http://www.elmundo.es/diccionarios/ [Consulta: 2010, 1 de mayo].

El País (1999). Libro de estilo. Madrid: Ediciones El País. Disponible en: http://estudiantes.elpais.es/libroestilo/indice_estil os.htm/ [Consulta: 2010, 1 de mayo].

Gombert, J. É. (1999). Metalinguistic Development. Chicago: University of Chicago Press.

Grice, H. P. (1975). Logic and conversation. En P. Cole \& J. L. Morgan (eds.), Syntax and Semantic. Speech Acts (pp. 41-58). Nueva York: Academic Press.

Hymes, D. H. (1971). Acerca de la competencia comunicativa. En Llobera et al. (1995). Competencia comunicativa. Documentos básicos en la enseñanza de lenguas extranjeras (pp. 2747). Madrid: Edelsa.

LOE (2006). Ley Orgánica de Educación 2/2006, de 3 de mayo. Madrid: Ministerio de Educación.

Portolés, J. (2004). Pragmática para hispanistas. Madrid: Síntesis.

Pratt, C. \& Nesdale, A. R. (1984). Pragmatic Awareness in Children. En W. E. Tunmer, C. Pratt \& M. L. Herriman (eds.), Metalinguistic Awareness in Children (pp. 105-127). Berlín: Springer-Verlag.

Real Academia Española (2001). Diccionario de la Real Academia. Madrid: Espasa Calpe. Disponible en: http://www.rae.es [Consulta: 2010, 1 de mayo].

Real Academia Española (2005). Diccionario Panhispánico de Dudas. Madrid: Santillana. Disponible en: http://www.rae.es [Consulta: 2010, 1 de mayo].
Reyes, G. (2002). Metapragmática. Lenguaje sobre lenguaje, ficciones, figuras. Valladolid: Universidad de Valladolid.

Romeo Escobar, A., Sales Garrido, L. M., Domínguez García, I., Pérez Bello, T., Rodríguez Fleitas, X. \& Toledo Costa, A. (2007). El enfoque cognitivo, comunicativo y sociocultural en la enseñanza de la lengua y la literatura. Ciudad de La Habana: Editorial Pueblo y Educación.

Van Ek, J. (1986). Objectives for Foreign Language Learning (Vol I.). Estrasburgo: Council of Europe.

Verschueren, J. (2002). Notes on the role of metapragmatic awareness in language use. Pragmatics 10 (4), 439-456.

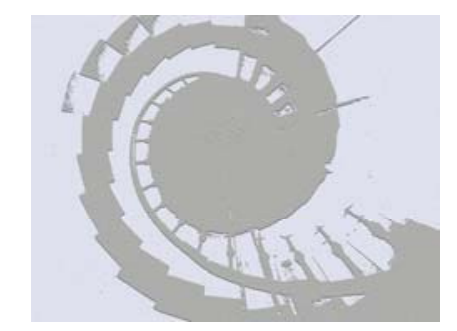

ANEXO.

Planteamiento didáctico: Las correcciones de estilo periodístico.

Curso: $3^{\circ}$ de ESO (LOE, 2006).

Índice.
a. Objetivos
b. Contenidos
c. Competencias básicas
d. Actividades
e. Evaluación
f. Temporización
g. Recursos

Objetivos.

- Acercar al alumno al mundo de la prensa escrita.

- Acrecentar el interés por la lectura periodística.

- Dar a conocer la profesión de corrector de estilo periodístico: formas de acceso, método de trabajo y herramientas.

- Insistir en la funcionalidad de los diccionarios en las tareas de corrección periodística. 
- Conocer qué son los libros de estilo y cuál es su estructura.

- Consultar el libro de estilo de algún medio escrito con alcance nacional (El Mundo, El País).

- Aplicar criterios normativos en la corrección ortográfica y gramatical de los textos.

- Prestar atención a los errores sintácticos más frecuentes: desorden oracional, separación de sujeto y verbo mediante comas y otros procedimientos, confusión de estilo directo e indirecto.

- Atender a la variación e inestabilidad del léxico en la lengua y aplicar criterios normativos y descriptivos en la adaptación de extranjerismos y neologismos.

- Buscar la claridad, precisión e imparcialidad en los géneros de información, principalmente en la noticia.

- Evitar la ambigüedad y la subjetividad en los géneros informativos.

- Evitar el uso de vulgarismos, determinados cultismos, dialectalismos, polisílabos, tecnicismos y palabras de argot en los géneros informativos.

- Conocer la estructura jerárquica de la noticia.

- Eludir la repetición de unidades léxicas próximas entre sí en un texto mediante sinonimia.

- Conocer el uso tipográfico más extendido en los diarios: negrita, cursiva, comillas, sangrías e interlineados.

- Conocer algunos elementos de la titulación y aprender a titular una noticia.

- Saber cuáles son los principales recursos en línea útiles en la corrección de estilo.

- Corregir adecuadamente una noticia con deficiencias claras de redacción.

- Apreciar el papel y los efectos que tienen los medios y, en particular, el de las noticias en la sociedad contemporánea.

- Ser conscientes de la importancia de la coherencia, la claridad y la corrección lingüísticas en la transmisión de información en prensa.

- Valorar la lengua como elemento necesario para la vida laboral.

\section{Contenidos.}

Los contenidos se distribuyen en dos apartados y un anexo. La segunda sección constituye el núcleo de esta unidad didáctica:

1. La profesión de corrector de estilo periodístico.

2. El libro de estilo periodístico.

2.1. Estructura del libro de estilo.
2.2. Criterios de corrección periodística.

2.2.1. Nivel ortográfico.

2.2.2. Nivel léxico.

2.2.3. Nivel sintáctico.

2.2.4. Cuestiones tipográficas, maquetación y titulación.

ANEXO: La noticia

\section{Competencias básicas.}

- Tratamiento de la información y competencia digital: aplicar los principales recursos y herramientas en soporte papel y electrónico necesarios en la corrección de estilo periodístico.

- Competencia social: familiarizarse y poner en práctica el método de trabajo de un corrector de estilo periodístico.

- Tratamiento y gestión autónoma de la información lingüística: usar del diccionario con fines normativos en la corrección de textos.

- Competencia sociocultural: comprender la funcionalidad, el ámbito de uso y la estructura de los libros de estilo.

- Competencia comunicativa escrita: reconocer faltas ortográficas graves en la lengua común.

- Competencia comunicativa oral y escrita: discernir errores gramaticales graves en la lengua ordinaria.

- Competencia comunicativa escrita: explorar y descubrir las posibles deficiencias léxicas en un texto informativo.

- Competencia comunicativa oral y escrita: proponer sinónimos adecuados para palabras de uso común repetidas en el discurso.

- Competencia sociocultural: observar las principales características de los textos informativos que aparecen en la prensa diaria y comprender la estructura jerárquica de la noticia.

- Competencia digital: usar correctamente los tipos de letra, la cursiva y la negrita.

- Competencia comunicativa de síntesis: elaborar un titular y un subtítulo adecuados a una noticia y evitar en ellos el sensacionalismo.

- Competencia de aprendizaje autónomo y trabajo personal: realizar individualmente las tareas de corrector de estilo aplicándolas a un texto de información con deficiencias de redacción.

\section{Actividades.}

En esta unidad se propone una única actividad individual que consta de dos partes diferentes:

1. Elaborar un titular y un subtítulo para una noticia concreta. 
2. Revisar la noticia aplicando los criterios propios de un corrector de estilo periodístico, prestando especial atención a la ortografía, a la sintaxis, al léxico y, en lo posible, a la tipografía del texto.

Se entregarán dos modelos con textos diferentes, para que no todos los alumnos tengan que titular y corregir la misma noticia. El texto será, en cualquiera de los dos casos, informativo y de actualidad; tendrá una extensión de veinte líneas aproximadamente y contendrá fallos de edición, así como errores lingüísticos introducidos por el profesor (entre doce y trece fallos).

Finalmente, se recordará a los alumnos en qué aspectos lingüísticos deben fijar su atención para la corrección del texto: (1) faltas ortográficas y puntuación; (2) léxico inadecuado: extranjerismos, polisílabos, vulgarismos, proponer sinónimos, evitar repeticiones de palabras que se encuentran próximas en el texto; (3) sintaxis deficiente: estructuras gramaticales mal construidas, errores de concordancia, confusiones de estilo directo y diferido, comas entre sujeto y verbo, comas antepuestas a conjunciones copulativas; (4) tipografía: extranjerismos y latinismos en cursiva, citas textuales entrecomilladas.

\section{Evaluación.}

Para superar la unidad, el alumno habrá de detectar un mínimo de seis o siete fallos de redacción en la actividad propuesta. La calificación se expresará de forma cualitativa: «excelente», «notable», «bien», «suficiente» e «insuficiente».
En la primera parte de la actividad se valorará positivamente:

1. El carácter sintético y la concisión del titular y del subtítulo.

2. La adecuación del titular y del subtítulo con el contenido del texto.

3. El alejamiento de cualquier tipo de sensacionalismo.

4. La no repetición de palabras y/o datos en el titular y el subtítulo.

El principal criterio de evaluación que se tendrá en cuenta será: corregir una noticia de actualidad e identificar, al menos, seis o siete errores ortográficos, sintácticos, léxicos y tipográficos cometidos en la redacción.

\section{Temporización.}

La explicación de la unidad didáctica tendrá una duración de cien minutos (dos sesiones de cincuenta minutos cada una). La actividad se realizará en casa haciendo uso de los principales recursos impresos y/o electrónicos que el profesor mencionará en clase. Los alumnos contarán con aproximadamente cinco días para completar y entregar la actividad y tendrán los resultados a la semana. Una vez corregida la tarea, se invertirán unos veinte minutos de otra sesión para comentar la actividad y analizarla conjuntamente.

\section{Recursos.}

ㅁ Diccionario de la Real Academia Española $22^{\mathrm{a}}$ ed., 2001

口 Diccionario Panhispánico de Dudas $1^{\text {a }}$ ed., 2005

$\square$ www.rae.es

$\square$ http://estudiantes.elpais.es/libroestilo/indice_e stilos.htm

$\square$ http://www.elmundo.es/diccionarios/ 